\title{
Impact of mobile advertising wearout on consumer irritation, perceived intrusiveness, engagement and loyalty: A partial least squares structural equation modelling analysis
}

\begin{tabular}{|c|c|}
\hline \multicolumn{2}{|c|}{$\begin{array}{l}\text { Authors: } \\
\text { Ahmad A.M. Alwreikat }{ }^{1} \text { (D) } \\
\text { Husam Rjoub }{ }^{1} \text { (D) }\end{array}$} \\
\hline \multicolumn{2}{|c|}{$\begin{array}{l}\text { Affiliations: } \\
{ }^{1} \text { Department of Accounting, } \\
\text { Faculty of Economics and } \\
\text { Administrative Sciences, } \\
\text { Cyprus International } \\
\text { University, Nicosia, Cyprus }\end{array}$} \\
\hline \multicolumn{2}{|c|}{$\begin{array}{l}\text { Corresponding author: } \\
\text { Ahmad Alwreikat, } \\
\text { ahmad.alwreikat@yandex. } \\
\text { com }\end{array}$} \\
\hline \multicolumn{2}{|c|}{$\begin{array}{l}\text { Dates: } \\
\text { Received: } 04 \text { Apr. } 2020 \\
\text { Accepted: } 30 \text { Oct. } 2020 \\
\text { Published: } 21 \text { Dec. } 2020\end{array}$} \\
\hline \multicolumn{2}{|c|}{$\begin{array}{l}\text { How to cite this article: } \\
\text { Alwreikat, A.A.M., \& } \\
\text { Rjoub H., (2020). Impact of } \\
\text { mobile advertising wearout } \\
\text { on consumer irritation, } \\
\text { perceived intrusiveness, } \\
\text { engagement and loyalty: } \\
\text { A partial least squares } \\
\text { structural equation modelling } \\
\text { analysis. South African } \\
\text { Journal of Business } \\
\text { Management 51(1), a2046. } \\
\text { https://doi.org/10.4102/ } \\
\text { sajbm.v51i1.2046 }\end{array}$} \\
\hline \multicolumn{2}{|c|}{$\begin{array}{l}\text { Copyright: } \\
\text { (C) 2020. The Authors. } \\
\text { Licensee: AOSIS. This } \\
\text { is licensed under the } \\
\text { Creative Commons } \\
\text { Attribution License. }\end{array}$} \\
\hline \multicolumn{2}{|l|}{ Read online: } \\
\hline 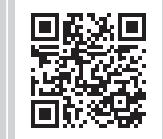 & $\begin{array}{l}\text { Scan this QR } \\
\text { code with your } \\
\text { smart phone or } \\
\text { mobile device } \\
\text { to read online. }\end{array}$ \\
\hline
\end{tabular}

Purpose: Mobile and smart devices provide a platform for firms/brands to communicate directly with past, present, or potential consumers (via online pop-ups, sponsored ads, ads on social media messengers, timelines, and walls, etc.). Intense competition among firms and brands resulted in repetitive exposures to Ads by consumers. Existing research on human-mobile interaction and end-user mobile management only highlights the positive fronts of repetitive exposures to mobile ads, ignoring the negative. The present study examines the effects of Mobile Ad Wearout on irritation, intrusiveness, engagement, and loyalty via social media outlets.

Design/methodology/approach: Survey data were solicited from consumers in Jordan and partial least squares structural equation modeling (PLS-SEM) was applied on data $(n=388)$.

Findings: The PLS-SEM results show that Mobile Ad Wearout is a strong determinant for increased perceived consumer irritation and intrusiveness. Intrusiveness resulted in lower levels of consumer engagement and higher levels of consumer loyalty. Irritation resulted in lower levels of consumer engagement; no changes were observed in consumer loyalty

Practical implications: The study shows managers how Mobile Ad Wearout causes irritation and intrusiveness, which in turn diminishes consumer engagement and loyalty. In essence, managers can gain insights on the positive and negative outcomes of Mobile Ad Wearout.

Originality/value: This study expands the conceptualization of repetitive mobile Ads by showing the negative fronts of mobile Ads. Implications for theory and practice offered, limitations and future research directions are discussed.

Keywords: mobile wearout; consumer engagement; consumer loyalty; consumer anger, irritation; intrusiveness.

\section{Introduction}

Mobile and smart devices are changing the way customers and businesses interact with each other, such as through personalised experiences and advertisements (Bhadoria, Chaudhari, Tomar, \& Singh, 2017). eMarketer (2015) showed that about $88 \%$ of US firms are using at least one social networking site (Twitter, Facebook, Instagram, Pinterest, Snapchat, etc.) for marketing purposes. Internet World Stats (2020) reported that this trend is expected to spread to other countries with a high literacy and Internet-penetration rate, such as Jordan (85.3\%). According to a Statista (2019) report, there has been a dramatic increase in the number of social media users from 0.97 billion in 2010 to 2.82 billion in 2019, worldwide. Facets of mobile technology that have been discussed and debated in the literature include ubiquity, deep learning, privacy issues and personalised advertisements (Gupta, Agrawal, \& Yamaguchi, 2019; Gupta, Yamaguchi, \& Agrawal, 2018; Jararweh et al., 2017; Mostafa, 2011). Personalised marketing and advertisements via mobile and social media outlets are expected to grow (Tucker, 2014).

Research showed that marketers and advertisers in the United States will spend around $\$ 43.9$ billion this year on mobile advertisements (ads) (Benes, 2019). Computing has become prevalent in personalised marketing, which is why mobile devices are highly individualised and are important personal communication tools (Bacile, Ye, \& Swilley, 2014). Shawky, Kubacki, Dietrich and Weaven (2019) argued that less accessible consumer segments can be reached through social media and mobile platforms ads. Existing literature shows that 
personalised mobile ads are antecedents of high brand loyalty, brand attachment, brand engagement, positive attitude, perceived quality and intention to forward the ads (e.g., Grewal, Bart, Spann, \& Zubcsek, 2016; Shanahan, Tran, \& Taylor, 2019; Tucker, 2014; Walrave, Poels, Antheunis, Van Den Broeck, \& Van Noort, 2019).

In this study, mobile ad wearout represents excessive exposure to the same marketing and advertising campaigns. Mobile and pop-up ads do not only affect the human-mobile interaction experience but also install negative feelings and, as such, are generally unwanted marketing and advertising channels. Past scholars focused mostly on the positive outcomes of mobile ads (Tucker, 2014; Walrave et al., 2019), which misled marketing managers to think that repetition and high exposure to personalised mobile ads is a way to attract and retain consumers. However, mobile ads can be disturbing because of the nature of their execution (e.g., too loud or too long) or placement (e.g., too many or too frequent), and their execution process may cause unfavourable spillover effects on marketing and advertising efforts (Brechman, Bellman, Robinson, Rask, \& Varan, 2016). The extant theoretical discussions illustrated that mobile ad wearout can cause privacy concerns, for example, intrusiveness and irritation amongst consumers.

There is an absence or the low quality of the customer relationship management and sales management systems in the Arabian ads industry which may hinder a firm's ability to balance ads strategies (Kalliny, 2012). Surprisingly, studies that investigated ad wearout were mostly in an offline context and in western nations (Pechmann \& Stewart, 1990; Peggy, 1999; Royo-Vela \& Meyer, 2016). To the best of the authors' knowledge, there are no studies on mobile ad wearout in the Arabian context. The aim of this article is to examine the impact of mobile ad wearout on perceived consumer intrusiveness and irritation, and the impact of perceived consumer intrusiveness and irritation on consumer loyalty and engagement. A partial least squares structural equation modelling (PLS-SEM) technique is deployed to examine these relationships.

The PLS-SEM technique showcases the variance explained in the outcome variable by the predictor variable (Hair, Hult, Ringle, \& Sarstedt, 2017), and its 'causal-predictive' power ensures a balance between theoretical construct explanation, causes and prediction (Abubakar \& Al-zyoud, 2020; Shmueli et al., 2019). The remainder of this article is organised as follows. In the 'Theoretical background and hypotheses' section, we review the literature on the concepts under investigation and conclude with the hypotheses development. In the 'Methods' section, we present the research instruments, data collection and sampling approach. The 'Analysis and results' section presents the research data analyses techniques and results, and the 'Discussion' section presents a discussion of the findings, implications, research limitations and future recommendations. The 'Conclusion' section presents the concluding statements.

\section{Theoretical background and hypotheses}

Mobile ad wear-in is a process by which consumers become familiar with the marketing and ad messages. According to Chen, Yang and Smith (2016), 'initial exposures to new ads and marketing messages create a positive feeling by reducing perceived uncertainty and serve as a medium for learning about brand and/or brand awareness' (p. 336). Mobile ad wearout occurs when consumers are repeatedly exposed to the same ads and marketing message (Pechmann \& Stewart, 1990; Peggy, 1999). Offline wearout has a negative effect on consumers' attitudes towards advertising and/or marketing messages of a brand or firm (Royo-Vela \& Meyer, 2016). Amongst other perceptions, perceived privacy invasion can change the effect of marketing campaigns from positive to negative attitudes towards the firm or brand (Mahmoud, Grigoriou, Fuxman, \& Reisel, 2020; Tsai, Egelman, Cranor, \& Acquisti, 2011; Tucker, 2014) and can cause irritation towards the campaigner (Lin \& Chen, 2015; Mahmoud, 2015).

Consumer irritation towards ads and marketing messages is defined as being more negative than mere dislike; it is 'provoking, causing displeasure and momentary impatience' (Aaker \& Bruzzone, 1985, p. 48). Ad content can cause irritation, such as from repetitive content, execution or placement, and with annoying pop-ups at private times or whilst chatting (Brechman et al., 2016; Duncan \& Nelson, 1985; Royo-Vela \& Meyer, 2016). Perceived consumer intrusiveness is the degree to which advertisements in a media vehicle interrupt the flow and goals of the viewer or consumer (Ha, 1996). Intrusiveness as a psychological consequence occurs when consumers' cognitive processes are interrupted, such as blocking or interrupting access to content. Intrusiveness and irritation are viewed as a major cause of annoyance and ad avoidance (Tsai et al., 2011; Tucker, 2014). On the other hand, brands and firms are interested in pursuing consumer loyalty and engagement because of their links to secure profitability and long-term sustainability (Shankar \& Jebarajakirthy, 2019).

Repetition allows consumers to process and digest advertisement and marketing messages easily. According to Alwitt and Mitchell (1985), a high number of message repetitions increases the level of persuasion and enhances the tendency to recall an advertisement's message. However, over time, repetition may result in wearout because high exposure frequencies induce expressions of displeasure and annoyance (Cacioppo \& Petty, 1979; Rau, Zhou, Chen, \& $\mathrm{Lu}, 2014)$. Repetition can arouse a feeling of tedium or psychological reactance that ultimately proves detrimental to persuasion (Rau et al., 2014). Incessant repetition affects consumers' perceptions of the firm's effort and credibility (Gaber, Wright, \& Kooli, 2019; Royo-Vela \& Meyer, 2016). In the context of this research, mobile ad wearout denotes the high frequency at which individuals are exposed to a mobile advertisement in a day. 
In human-mobile interaction experiences, the effect of repetition in mobile advertisements and marketing is initially positive, because consumers develop positive attitudes as familiarity increases. However, when familiarity reaches its saturation level, additional exposures to the same messages may result in negative thoughts about a product or service. Wearout can reduce ad effectiveness and brand preference (Goldstein, Suri, McAfee, Ekstrand-Abueg, \& Diaz, 2014). Research showed that more ad repetition can hurt a brand because consumers who encounter the same ads repeatedly can become weary and turned off (Kronrod \& Huber, 2019). Schmidt and Eisend's (2015) meta-analysis showed that the effect of traditional advertising repetition on consumer attitude can have both positive (e.g., habituation, positive thoughts like loyalty and recommendations) and negative outcomes (e.g., anger, boredom, etc.). This has received additional support from past work (Brechman et al., 2016; Tsai et al., 2011; Tucker, 2014). These relationships have received little attention in the context of mobile ads. In particular, how firms conduct their marketing and advertising campaigns, causing mobile ad wearout that leads to unwanted behavioural responses. Based on these arguments, the following hypotheses are proposed:

H1: Mobile ad wearout will influence perceived irritation amongst consumers.

H2: Mobile ad wearout will influence perceived intrusiveness amongst consumers.

Consumer engagement is a mental state of being attached to, engrossed with, and devoting attention to a firm or brand (Triantafillidou \& Siomkos, 2018). According to Hollebeek, Glynn and Brodie (2014), consumer engagement is a psychological state that:

$[E]$ volves through cognitive, affective and behavioral processes spanning from learning (gaining knowledge around brands), sharing (information and experiences), advocating (recommending brands), socializing (developing attitudes towards the community) and co-developing products. (p. 155)

Consumer loyalty is the tendency of a buyer to patronise a brand, product or firm revealed through behavioural and affective actions that can be quantified (i.e., increased commitment, continuance and repurchase), as noted by Keiningham, Aksoy and Williams (2009). In the context of mobile platforms, consumer loyalty reflects the tendency of users to regularly visit a brand's or firm's website and purchase and share positive, online word of mouth (WOM), as noted by Kaya, Behravesh, Abubakar, Kaya and Orús (2019).

Irritation evokes retaliatory behaviours towards the brand perceived to be responsible for the negative event and emotion. Negative emotions, such as irritation, anger, dislike and discontent can predict consumer behaviour (Romani, Grappi, \& Dalli, 2012; Sung \& Yih, 2019). Dickinger, Haghirian, Murphy and Scharl (2004) advised marketers to consider the frequency of ad messages sent to consumers, and Royo-Vela and Luna (2012) argued that a high rate of ad messages can lead to negative attitudes towards the brand or firm. These attitudes and behaviours are likely to encourage negative consumer behaviours such as complaining, boycotting, spreading negative WOM information, persuading other customers from purchasing the brand, and so forth (Abubakar, Ilkan, Al-Tal, \& Eluwole, 2017; Antonetti, 2016; Riaz \& Khan, 2016; Romani et al., 2012; Sung \& Yih, 2019). Mobile ad wearout resulted in lower click-through rates (the ratio of users who click on a specific link to the number of total users who view a page, email or advertisement) amongst consumers (Försch \& De Haan, 2018). Based on the extant theoretical claims, this study theorises that irritation may deteriorate the level of consumer engagement and loyalty:

H3: Consumer perceived irritation will influence consumer engagement.

H4: Consumer perceived irritation will influence consumer loyalty.

In a consumption context, intrusion evokes unwanted behaviours amongst consumers. From human-mobile device interaction perspective, end-user mobile management, privacy and security, and performance of apps are important in relation to mobile ad wearout, and repetitive ads can raise privacy concerns or the perception of intrusiveness (Grewal et al., 2016). These feelings are likely to encourage negative reactions towards the advertising and/or marketing messages (Tsai et al., 2011; Tucker, 2014). Research has shown that the intrusiveness of ads and marketing messages acts as an antecedent of negative attitudes, such as a reduction in click-through rates towards a firm or brand (Aguirre, Mahr, Grewal, De Ruyter, \& Wetzels, 2015; Schmidt \& Eisend, 2015). As the level of perceived intrusiveness of ads and marketing messages increases, consumers are likely to ignore them and exhibit weakened reactions towards the firm or brand. Based on the extant theoretical claims, this study theorises that perceived intrusiveness may deteriorate the level of consumer engagement and loyalty.

H5: Consumer perceived intrusiveness will influence consumer engagement.

H6: Consumer perceived intrusiveness will influence consumer loyalty.

\section{Methods}

\section{Measures}

Mobile ad wearout was assessed with a three-item measure from Royo-Vela and Meyer (2016); the items were modified to fit the context and interest of the present research. Consumers were asked to rate the extent to which they agreed with statements such as, 'This brand repeatedly sends the same mobile ads through (e.g., Facebook, Instagram, Twitter etc.)'.

Perceived consumer irritation was assessed with a two-item measure from Royo-Vela and Meyer (2016), which was adapted from Duncan and Nelson's (1985) studies. Consumers were asked to reflect upon the level of irritation 
caused by mobile ads by responding to items such as, 'I consider mobile advertising messages as irritating'.

Perceived consumer intrusiveness was assessed with a two-item measure from Li, Edwards and Lee (2002). Consumers were asked to rate the extent to which they agreed with statements such as 'I perceive mobile advertisements as intrusive'.

Consumer engagement was assessed with an eight-item measure from Hollebeek et al. (2014). Consumers were asked to rate the extent to which they agreed with statements such as 'I spend a lot of time using this online brand community compared to others'.

Consumer loyalty was assessed with a three-item measure from Keiningham et al. (2009), which was adapted from Noble, Griffith and Adjei (2006) to reflect consumer loyalty by responding to items such as 'As a customer, I am strongly loyal to this brand'. All the measures were operationalised on a five-point response format $(1=$ strongly disagree to $5=$ strongly agree). See Table 1-A1 for survey items.

\section{Sampling and data collection}

The original survey items were translated from English to Arabic and translated back by linguistic professionals. A pilot study was conducted with 15 participants to ensure that participants had no difficulties in understanding the questions, and some rephrasing and rewording were done to adhere to the target's cultural understandings. Jordan, officially the Hashemite Kingdom of Jordan, is an Arabian country with a population of approximately 10 million. According to the United Nations Educational, Scientific and Cultural Organisation (UNESCO), the literacy rate in the country is around $98.01 \%$. The context of this study suits the Jordanian population well, given the level of literacy, the number of mobile connections (8.23 million), the number of Internet users (6.78 million) and the number of social media users (5.70 million) as of 2020 (DatarePortal, 2020).

Participants were Jordanian consumers (the face-to-face survey was carried out in Amman, Jordan) recruited through a simple random sampling technique to acquire a representative sample and to increase the reliability of the research outcomes (Jahmani, Fadiya, Abubakar, \& Elrehail, 2018). In order to ensure that the surveys were carried out by accomplished sources, we used the filter question: 'Can you think of any brand/company that repeatedly sends you mobile ads via social media outlets (i.e., Facebook, Instagram, Twitter, LinkedIn and others)'. Those who said 'no' were excluded from the study. Those who said 'yes' were asked to name the brand/company and, in response to the ads messages they received, the respondents were asked to rate the study variables based on their perceptions and feelings. The use of filter question allows the researchers to select suitable and representable targets.
Participation was voluntary, and respondents were assured full confidentiality and anonymity to reduce common method bias (CMB) (Podsakoff, MacKenzie, \& Podsakoff, 2012). Consequently, statistical test was conducted because exogenous and endogenous variables were collected at the same time using a self-reported instrument. Harman single factor extraction denotes that a single factor explained only $32.38 \%$ of the total variance, below the $50 \%$ threshold. Thus, CMB should not be a major concern in this study (Podsakoff et al., 2012). A total of 600 survey packets were printed and 415 valid responses were retrieved, yielding a $69 \%$ response rate. Responses with missing values and incomplete information were eliminated; thus, 388 valid responses were used for analysis. Demographic variables considered in this study are gender, age, education and frequency of checking mobile phones (times), including at work, walking, whilst using the toilet and in-between sleep sessions. Results from a frequency analysis are illustrated in Table 1.

\section{Analysis and results Analytical framework}

There are two types of structural equation modelling (SEM) namely: covariance-based SEM (CB-SEM) and PLS-SEM. Covariance-based-SEM is mainly used for theory building, confirmation and rejection using robust multivariate assumptions. On the other edge, PLS-SEM is mainly used to illustrate the variance explained in the endogenous variable by the exogenous variable (Yakubu, Dasuki, Abubakar, \& Kah, 2020). Hair et al. (2017) stated that the PLS-SEM approach is suitable for exploratory, confirmatory and predictive analyses (Henseler, Hubona, \& Ray, 2016). Since the objective of this study is to predict the outcomes. This research work deploys PLS-SEM because of its 'causalpredictive' power that permits it to strike a balance between explanation and prediction (Shmueli et al., 2019).

TABLE 1: Demographic breakdown.

\begin{tabular}{lcc}
\hline Demographic variables & Frequency & \% \\
\hline Gender & 267 & 68.8 \\
Male & 121 & 31.2 \\
Female & 388 & 100.0 \\
Total & & \\
Age & 93 & 24.0 \\
Under 20 & 263 & 67.8 \\
21-30 & 4 & 1.0 \\
31-40 & 18 & 4.6 \\
41-50 & 10 & 2.6 \\
Over 51 & 388 & 100.0 \\
Total & & \\
Level of education & 0 & 0.0 \\
High school & 55 & 14.2 \\
Some college & 134 & 34.5 \\
Bachelor's degree & 199 & 51.3 \\
Higher degree & 388 & 100.0 \\
Total & & \\
Frequency of checking mobile phones (times) & 55 & 14.2 \\
1-15 times & 267 & 68.8 \\
16-30 times & 66 & 17.0 \\
More than 30 times & 388 & 100.0 \\
Total & &
\end{tabular}


Following Ringle, Wende and Becker's (2015) recommendation, a PLS-SEM technique was applied to test the proposed hypotheses (SmartPLS 3 software). Table 2 presents the reliability and convergent validity of the measurement model. Firstly, indicators with the standardised factor loadings above 0.50 were retained (see Figure 1, outer model) and were statistically significant above 1.960 (see Figure 2, outer model). Three indicators from the consumer engagement variable were eliminated because of low factor loading (refer to Table 1-A1 for eliminated items). Table 2 illustrates that the Cronbach alpha $(\alpha)$, Dijkstra-Henseler's reliability (rho_A) and the composite reliability (CR) of the variables under investigation have values above the threshold of 0.70 . These results collectively demonstrate adequate construct reliability and internal consistency.

Secondly, Table 2 illustrates that the variables under investigation have exhibited an average variance extracted (AVE) that is greater than the 0.50 threshold

TABLE 2: Reliability and convergent validity.

\begin{tabular}{lcccc}
\hline Variables & $\boldsymbol{\alpha}$ & Rho_A & CR & AVE \\
\hline Mobile ad wearout & 0.912 & 0.917 & 0.945 & 0.851 \\
$\begin{array}{l}\text { Perceived consumer } \\
\text { irritation }\end{array}$ & 0.870 & 0.870 & 0.939 & 0.885 \\
$\begin{array}{l}\text { Perceived consumer } \\
\text { intrusiveness }\end{array}$ & 0.881 & 0.885 & 0.944 & 0.893 \\
$\begin{array}{l}\text { Consumer engagement } \\
\text { Consumer loyalty }\end{array}$ & 0.755 & 0.760 & 0.835 & 0.504 \\
\hline
\end{tabular}

$C R$, composite reliability $\geq 0.70 ; A V E$, average variance extracted $\geq 0.50 ; \alpha$, Cronbach's alpha $\geq 0.70$; Rho_A $\geq 0.70$.
(Hair et al., 2017), suggesting the adequate convergent validity of each variable. The Fornell-Larcker matrix and heterotrait-monotrait ratio of correlations (HTMT index) were deployed to examine the divergent validity (the parameter showing that each variable explains more of the variance of its indicators than the indicators of the other constructs) of the variables under investigation. Table 3 illustrates that none of the inter-correlations were above the square root of each variable AVE (in bolddiagonal); this satisfies the criterion for divergent validity (Fornell \& Larcker, 1981; Yakubu et al., 2020). Table 4 illustrates that the HTMT indices for all the variables were less than 0.90; this provides additional evidence for divergent validity (Henseler et al., 2016).

\section{Hypotheses testing}

Concerning the effects of mobile ad wearout, the findings from the PLS-SEM in Table 5 reflect a positive and significant impact of this variable on perceived consumer irritation $(\beta=0.379, p=0.000)$ and perceived consumer intrusiveness $(\beta=0.542, \rho=0.000)$, which corroborates Hypotheses 1 and 2, respectively. Figure 1 shows that mobile ad wearout explains $14 \%$ and $29 \%$ of the variance of perceived consumer irritation and consumer intrusiveness. In relation to the effects of perceived consumer irritation, a negative and significant impact of this variable on consumer engagement was obtained $(\beta=-0.163, p=0.033)$, and the impact on consumer loyalty $(\beta=0.042, p=0.638)$

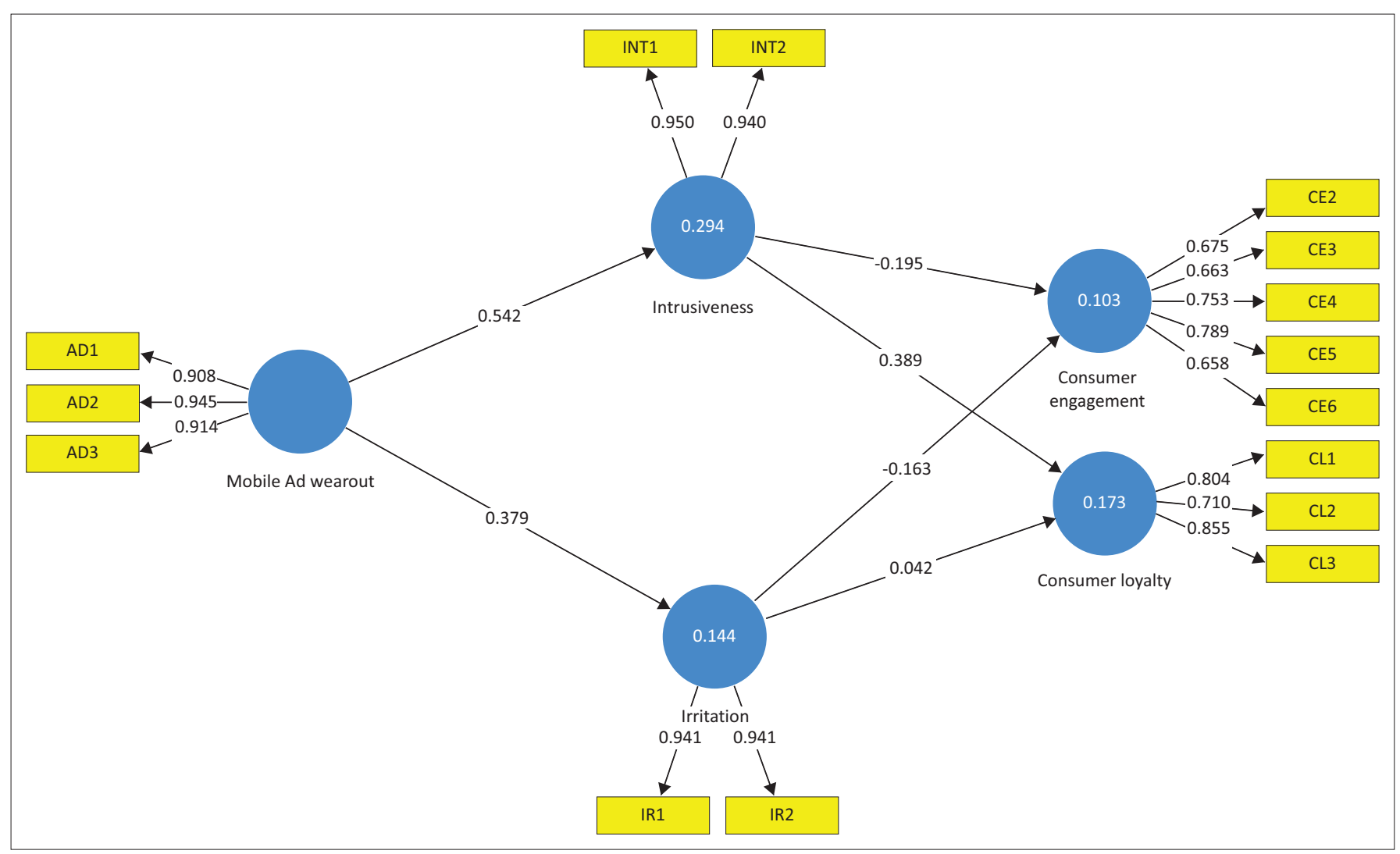

INT, intrusiveness; $\mathrm{CL}$, consumer engagement; $\mathrm{CE}$, consumer loyalty.

FIGURE 1: Factor loadings of the indicators, beta, and $R^{2}$ values. 


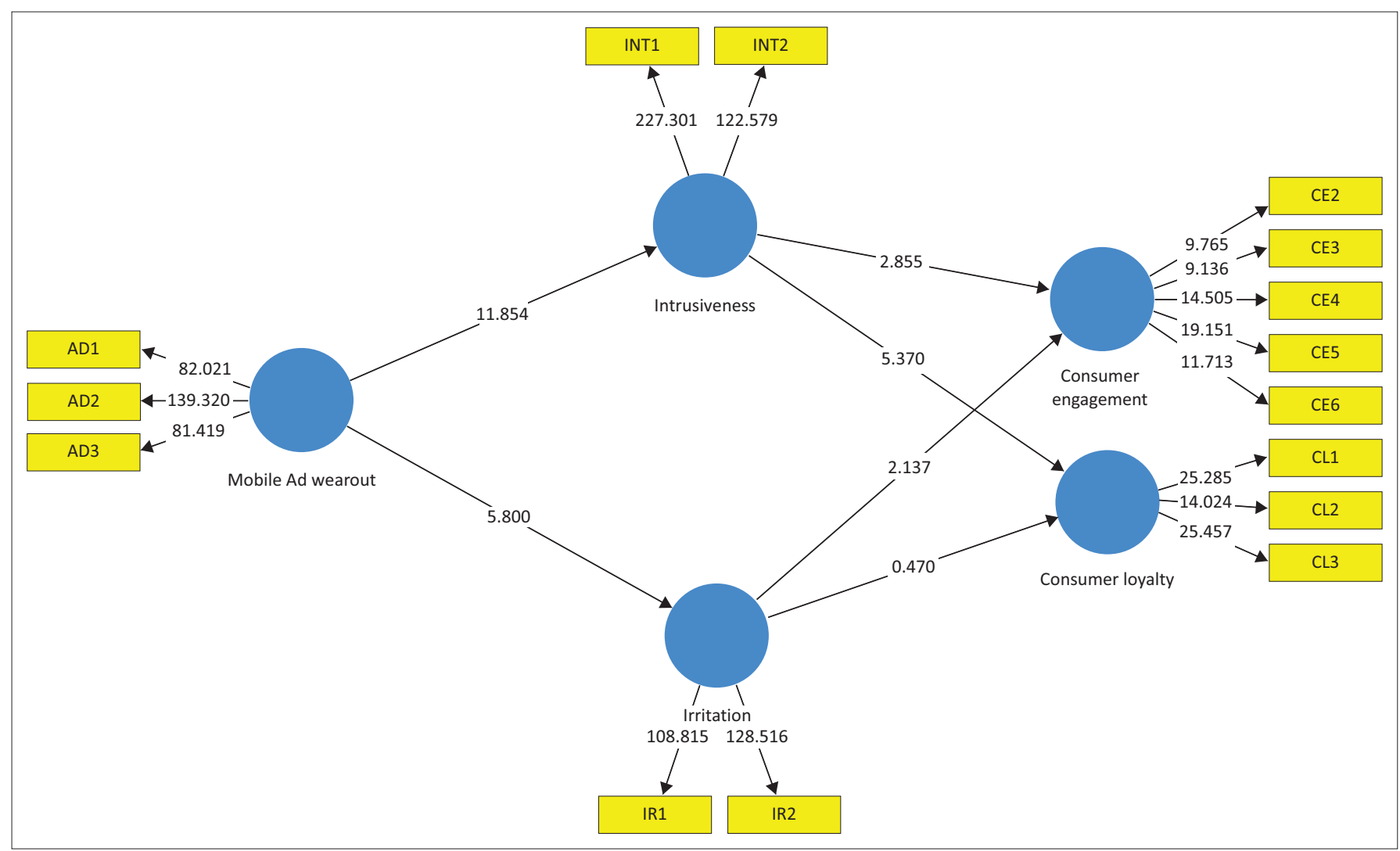

INT, intrusiveness; $C L$, consumer engagement; $C E$, consumer loyalty.

FIGURE 2: T-statistics of the indicators and beta coefficients.

TABLE 3: Divergent validity using Fornell-Larcker matrix.

\begin{tabular}{lccccc}
\hline Variables & $\mathbf{1}$ & $\mathbf{2}$ & $\mathbf{3}$ & $\mathbf{4}$ & $\mathbf{5}$ \\
\hline Mobile ad wearout & 0.922 & - & - & - & - \\
Perceived consumer irritation & 0.379 & 0.941 & - & - & - \\
Perceived consumer intrusiveness & 0.542 & 0.603 & 0.945 & - & - \\
Consumer engagement & -0.11 & -0.28 & -0.293 & 0.71 & - \\
Consumer loyalty & 0.387 & 0.276 & 0.414 & -0.11 & 0.792 \\
\hline
\end{tabular}

Note: Values above the diagonal in bold are squared inter-construct correlations for the Fornell-Larcker criterion.

TABLE 4: Divergent validity using heterotrait-monotrait index.

\begin{tabular}{lccccc}
\hline Variables & $\mathbf{1}$ & $\mathbf{2}$ & $\mathbf{3}$ & $\mathbf{4}$ & $\mathbf{5}$ \\
\hline Mobile ad wearout & - & - & - & - & - \\
Perceived consumer irritation & 0.424 & - & - & - & - \\
Perceived consumer intrusiveness & 0.603 & 0.691 & - & - & - \\
Consumer engagement & 0.146 & 0.331 & 0.356 & - & - \\
Consumer loyalty & 0.390 & 0.284 & 0.472 & 0.214 & - \\
\hline
\end{tabular}

was insignificant. This confirms Hypothesis 3 and disconfirms Hypothesis 4.

In relation to the effects of perceived consumer intrusiveness, a negative and significant impact of perceived consumer intrusiveness on consumer engagement was obtained $(\beta=-0.195, p=0.004)$, as well as a positive and significant impact on consumer loyalty $(\beta=0.389, p=0.000)$ (see Table 5). This confirms Hypothesis 5 and disconfirms Hypothesis 6. Figure 1 shows that consumer irritation and perceived consumer intrusiveness, collectively, explain $10 \%$ of the variance of consumer engagement. Whereas, perceived consumer intrusiveness explains $17 \%$ of the variance of consumer loyalty.

\section{Supplementary analysis}

This study did not dictate or hypothesise the presence of mediatory effects. To discover the process through which consumers seek refuge from mobile ad wearout, a test for mediation was carried out. Sobel's test has been criticised for being overly conservative because of its flawed sampling distribution assumptions and biased estimation. Bootstrapping overcomes this problem by resampling the dataset through simulation, in other words, estimating the indirect effect in each resampled dataset using confidence intervals for the indirect effect. Thus, a more rigorous and powerful mediation test, 'bootstrapping', with a resample of $n=5000$, was deployed (Zhao, Lynch, \& Chen, 2010).

To test for the indirect effects, the author(s) assessed the biascorrected bootstrap confidence intervals. The indirect effect of mobile ad wearout on consumer engagement through perceived consumer irritation was $\beta=-0.062, p=0.037$ and was statistically significant at the $95 \%$ confidence interval $(-0.120 ;-0.002)$. The indirect effect of mobile ad wearout on consumer loyalty through perceived consumer irritation was $\beta=0.016, p=0.650$ and was statistically insignificant at the $95 \%$ confidence interval $(-0.053 ; 0.086)$. Based on these results, we conclude that perceived consumer irritation fully mediates the link between mobile ad wearout on consumer engagement and not with loyalty (see Table 6).

The indirect effect of mobile ad wearout on consumer engagement through perceived consumer intrusiveness 
TABLE 5: Direct effects.

\begin{tabular}{|c|c|c|c|c|c|c|c|}
\hline Independent variable & Dependent variable & Sign & $\beta$ & $t$ & $p$ & $f^{2}$ & Decision \\
\hline H1: Mobile ad wearout & -> Perceived consumer irritation & + & 0.379 & 5.8 & 0 & 0.168 & Supported \\
\hline H2: Mobile ad wearout & -> Perceived consumer intrusiveness & + & 0.542 & 11.854 & 0 & 0.417 & Supported \\
\hline H3: Perceived consumer irritation & $\rightarrow$ Consumer engagement & - & -0.163 & 2.137 & 0.033 & 0.019 & Supported \\
\hline H4: Perceived consumer irritation & -> Consumer loyalty & - & 0.042 & 0.47 & 0.638 & 0.001 & Not supported \\
\hline H5: Perceived consumer intrusiveness & -> Consumer engagement & - & -0.195 & 2.855 & 0.004 & 0.027 & Supported \\
\hline H6: Perceived consumer intrusiveness & -> Consumer loyalty & - & 0.389 & 5.37 & 0 & 0.117 & Not supported \\
\hline
\end{tabular}

$\beta$, coefficient; $f^{2}$, effect size.

TABLE 6: Indirect effects.

\begin{tabular}{lccc}
\hline Indirect effects & Coefficients & $\boldsymbol{t}$ & $\boldsymbol{p}$ \\
\hline $\begin{array}{l}\text { Mobile ad wearout -> Perceived consumer } \\
\text { irritation -> Consumer engagement }\end{array}$ & -0.062 & 2.086 & 0.037 \\
$\begin{array}{l}\text { Mobile ad wearout -> Perceived consumer } \\
\text { irritation -> Consumer loyalty }\end{array}$ & 0.016 & 0.453 & 0.65 \\
$\begin{array}{l}\text { Mobile ad wearout -> Perceived consumer } \\
\text { intrusiveness-> Consumer engagement }\end{array}$ & -0.106 & 2.699 & 0.007 \\
$\begin{array}{l}\text { Mobile ad wearout -> Perceived consumer } \\
\text { intrusiveness-> Consumer loyalty }\end{array}$ & 0.211 & 4.656 & 0 \\
\hline
\end{tabular}

was $\beta=-0.106, p=0.007$ and was statistically significant at the $95 \%$ confidence interval $(-0.181 ;-0.026)$. The indirect effect of mobile ad wearout on consumer loyalty through perceived consumer intrusiveness was $\beta=0.211, p=0.000$ and was statistically significant at the $95 \%$ confidence interval $(0.127 ; 0.304)$. Based on these results, we conclude that perceived consumer intrusiveness fully mediates the link between mobile ad wearout and consumer engagement, and link between mobile ad wearout and consumer loyalty (see Table 6).

\section{Discussion}

In this study, we examine how mobile ad wearout experienced by consumers influences their irritation and perceived intrusiveness. We went further to examine how increased irritation and perceived intrusiveness may lower consumer engagement and loyalty. Firstly, mobile ad wearout influences perceived consumer irritation and consumer intrusiveness. It is worth noting that our findings are consistent with prior work (Brechman et al., 2016; Kronrod \& Huber, 2019; Mahmoud, 2013; Tsai et al., 2011; Tucker, 2014). The present findings validate those tested for offline ad wearout and in western nations. This gives scope to a broader theoretical view of the consequences of mobile ad wearout on consumer responses in the Arabian culture.

Secondly, we found that perceived consumer irritation reduces consumer engagement. This implies that events such as disappointment and perceived consumer irritation contribute negatively to engagement and involvement with a firm or brand. This makes sense, as consumers' attachment to a brand drives engagement (Hinson, Boateng, Renner, \& Kosiba, 2019), so a decline in attachment may result in lower levels of engagement. This outcome is consistent with prior work, which shows that negative emotions such as anger, discontent, dislike and worry can result in unwanted behavioural responses such as switching, complaining and negative WOM amongst consumers (e.g., Romani et al., 2012;
Sung \& Yih, 2019). We extend the literature to mobile ads domain by showing how perceived consumer irritation result in unwanted behavioural responses such as lower consumer engagement. Although existing literature theorised a negative association between perceived consumer irritation and loyalty (Grewal et al., 2016; Schmidt \& Eisend, 2015), it appears that irritation did not reduce consumer loyalty. Similar findings were echoed by Magin, Algesheimer, Huber and Herrmann (2003). Nordhielm (1996, p. 2) added that 'people's affective response to an overexposure of ads or marketing campaigns is either no longer positive or it shows a significant decline'. A plausible reason can be that irritation is at stake, or people are in an unchangeable mode. Nonetheless, further empirical research is needed, considering contextual variables such as switching barriers, frequency of ads, cyber culture, time spent with a mobile, service and product quality.

Third, we found that perceived consumer intrusiveness reduces consumer engagement. This implies that consumers' heightened privacy and intrusion concerns weaken their engagement with a firm or brand. Earlier scholars recorded a negative and significant association between similar variables such as direct email, click-rates and website-revisit intention (Aguirre et al., 2015; Grewal et al., 2016; Mahmoud, 2015; Mahmoud et al., 2019; Schmidt \& Eisend, 2015) as well as perceived mobile app intrusion and usage behaviour (Amos, Zhang, \& Pentina, 2014). This study has provided additional evidence using consumer engagement as an outcome. In addition, we recorded a positive and significant relationship between perceived consumer intrusiveness and consumer loyalty. The present outcome delineates that as perceived consumer intrusiveness increases, consumer loyalty towards the firm or brand increases. This contradicts the initial prediction, as we expected consumer loyalty to decline. The conflicting result illustrates a need to further investigate the role of contextual variables such as information sensitivity of the consumers, number of alternative brands, switching barriers, frequency of ads, cyber culture, time spent with a mobile and quality.

\section{Implications for theory and practice}

Several implications were drawn from the findings. Firstly, the findings suggest that mobile marketing campaigns in Jordan should be done with tactics to make the ads and marketing information enjoyable and fresh in consumer minds; this way, irritation and intrusion perception can be avoided. Prior research shows that mobile ad wearout is less 
likely to occur with lesser-known brands, as additional exposures may still be informative (Försch \& De Haan, 2018; Srinivasan, Pauwels, Silva-Risso, \& Hanssens, 2009). In this view, firms may categorise consumers based on the level of their engagement, that is, highly engaged consumers should have minimal exposure to mobile ads, whilst those with a low level of engagement can be exposed to additional ads to stimulate a taste for the company's product or services.

Secondly, marketers may adopt a strategy by which consumers are repeatedly exposed to mobile ads with limited interruption, with ample variations in execution to evade irritation and annoyance (Błachnio et al., 2018; Försch \& De Haan, 2018). Further, advertising-variation strategies have been shown to be more effective in terms of recall and thus can be useful tools for marketers in that they can lead to synergistic effects (Gebreselassie \& Bougie, 2019). Thirdly, managers must balance marketing campaigns to leverage the benefits of mobile ads and evade their consequential effects. For instance, mobile ads that provide justification for their offers stand a chance of boosting consumer loyalty and engagement (Grewal et al., 2016). To achieve this, ads should not appear in a self-serving or manipulative manner, because ads' presentations can influence marketing campaign efforts and privacy concerns. The use of an espousal system and online referrals (Abubakar, Ilkan, \& Sahin, 2016) can help mitigate consumer backlash triggered by perceptions of invasive and/or targeted ads.

Another interesting business implication is the inclusion of fun, interactive and entertaining content in mobile marketing and ads, as it is likely to reduce negative and induce positive reactions. Arabs in general share a similar culture and have greater tendency for homogeneity and group conformity (Hofstede, Hofstede, \& Minkov, 2005). A study by Mahajan (2013) found that Arabian consumers share similar traits and often react to a specific marketing mix in similar ways and manners. Although a 'one size fits all' strategy may not work for all Arabian consumers and countries, the findings in the Jordanian context provide important marketing-mix insights for managers in countries with similar demographic and cultural features. For example, marketing managers in countries such as Lebanon, Egypt and Saudi Arabia can benefit from the unveiled insights in this study.

In sum, our findings show that for marketing ads and campaigns that are sent within short time intervals, such campaigns should have a planned time lag after the initial exposure to minimise negative reactions. The use of the simple random sampling technique and a suitable sample selection, using filter questions, allowed the researchers to obtain responses from a representative sample. In addition, a set of stringent statistical tests to establish reliability and validity of the measures were conducted. In sum, the extant methodological and statistical approaches ensured the robustness of the method, and they also allowed the researchers to make concrete inferences based on the outcomes.

\section{Limitations and future research directions}

This study has several limitations that are worth mentioning. Firstly, we cannot ascertain causal order, because the data are cross-sectional. Secondly, the study uses a self-reported approach, which is vulnerable to CMB. Thirdly, single-source data, as respondents are all from a single country and culture, limit our ability to generalise the findings. Fourthly, the present study did not consider important contextual variables. To wrap up, we recommend that future studies utilise advanced methods such as longitudinal and experimental design (Podsakoff et al., 2012; Zhao et al., 2010), fuzzy sets (Kaya, Abubakar, Behravesh, Yildiz, \& Mert, 2020), Bayesian networks (Wipulanusat, Panuwatwanich, Stewart, Arnold, \& Wang, 2020), and predictive analytics and artificial intelligence techniques (Abubakar, 2018, 2019). How the findings generalise to other cultural contexts warrants further research. Thus, researchers are encouraged to consider the following contextual variables: information sensitivity of the consumers, number of alternative brands, switching barriers, frequency of ads, cyber culture, time spent with a mobile, service and product quality.

\section{Conclusion}

This study investigated the impact of mobile ad wearout on Jordanian consumer's irritation and perceived intrusiveness, and their impacts on consumer engagement and loyalty. Stringent tests and robust methodological approaches were carried out. Results revealed that mobile ad wearout is a strong determinant for increased irritation and perceived intrusiveness amongst consumers. Results show that as consumer irritation increases, the level of consumer engagement decreases, and no change was recorded with regard to consumer loyalty. Further, as perceived intrusiveness increases, the level of consumer engagement decreases, and the level of consumer loyalty increases. Marketing managers should consider both the positive and negative fronts of mobile ads prior to inaugurating them into their marketing mix.

\section{Acknowledgements Competing interests}

The authors have declared that no competing interests exist.

\section{Authors' contributions}

All authors contributed equally to this work.

\section{Funding information}

This research received no specific grant from any funding agency in the public, commercial or not-for-profit sectors.

\section{Ethical consideration}

This article followed all ethical standards for carrying out research. 


\section{Data availability statement}

The data that support the findings of this study are available from the corresponding author, upon reasonable request.

\section{Disclaimer}

The views and opinions expressed in this article are those of the authors and do not necessarily reflect the official policy or position of any affiliated agency of the authors.

\section{References}

Aaker, D.S., \& Donald, E.B. (1985). Causes of irritation in advertising. Journal of Marketing, 49(2), 47-57. https://doi.org/10.1177/002224298504900204

Abubakar, A.M. (2018). Linking work-family interference, workplace incivility, gender and psychological distress. Journal of Management Development, 37(3), 226-242. https://doi.org/10.1108/JMD-06-2017-0207

Abubakar, A.M. (2019). Using hybrid SEM-artificial intelligence approach to examine the nexus between boreout, generation, career, life and job satisfaction. Personnel Review, 49(1), 67-86. https://doi.org/10.1108/PR-06-2017-0180

Abubakar, A.M., \& Al-zyoud, M.F. (2020). Problematic Internet usage and safety behavior: Does time autonomy matter? Telematics and Informatics, 101501 https://doi.org/10.1016/j.tele.2020.101501

Abubakar, A.M., Ilkan, M., \& Sahin, P. (2016). eWOM, eReferral and gender in the virtual community. Marketing Intelligence \& Planning, 34(5), 692-710. https:// doi.org/10.1108/MIP-05-2015-0090

Abubakar, A.M., Ilkan, M., Al-Tal, R.M., \& Eluwole, K.K. (2017). eWOM, revisit intention, destination trust and gender. Journal of Hospitality and Tourism Management, 31, 220-227. https://doi.org/10.1016/j.jhtm.2016.12.005

Aguirre, E., Mahr, D., Grewal, D., De Ruyter, K., \& Wetzels, M. (2015). Unraveling the personalization paradox: The effect of information collection and trust-building strategies on online advertisement effectiveness. Journal of Retailing, 91(1) 34-49. https://doi.org/10.1016/j.jretai.2014.09.005

Alwitt, L.F., \& Mitchell, A.A. (1985). Psychological processes and advertising effect: Theory, research, and applications. London: Lawrence Erlbaum Associates.

Antonetti, P. (2016). Consumer anger: A label in search of meaning. European Journa of Marketing, 50(9/10), 1602-1628. https://doi.org/10.1108/EJM-08-2015-0590

Amos, C., Zhang, L., \& Pentina, I. (2014). Investigating privacy perception and behavior on Weibo. Journal of Organizational and End User Computing (JOEUC), 26(4), 43-56. https://doi.org/10.4018/joeuc.2014100103

Bacile, T.J., Ye, C., \& Swilley, E. (2014). From firm-controlled to consumer contributed: Consumer co-production of personal media marketing communication. Journal of Interactive Marketing, 28(2), 117-133. https://doi.org/10.1016/j.intmar. Interactive

Benes, R. (2019). Driven by social, native accounts for nearly two-thirds of display Ad spend. Retrieved from https://www.emarketer.com/content/driven-by-socialnative-accounts-for-nearly-two-thirds-of-display-ad-spend

Bhadoria, R.S., Chaudhari, N., Tomar, G.S., \& Singh, S. (Eds.). (2017). Exploring enterprise service bus in the service-oriented architecture paradigm. Hershey, PA: IGI Global. https://doi.org/10.4018/978-1-5225-2157-0

Błachnio, A., Przepiórka, A., Wołońciej, M., Mahmoud, A.B., Holdoš, J., \& Yafi, E. (2018). Loneliness, friendship, and Facebook intrusion: A study in Poland, Slovakia, Syria, Malaysia, and Ecuador. Studia Psychologica, 60(3), 183-194. https://doi.org/10.21909/sp.2018.03.761

Brechman, J., Bellman, S., Robinson, J.A., Rask, A., \& Varan, D. (2016). Limited interruption advertising in digital-video content: An analysis compares the effects of 'Midroll' versus 'Preroll' spots and clutter advertising. Journal of advertising research, 56(3), 289-298. https://doi.org/10.2501/JAR-2016-001

Cacioppo, J.T., \& Petty, R.E. (1979). Effects of message repetition and position on cognitive response, recall, and persuasion. Journal of Personality and Socia Psychology, 37(1), 97. https://doi.org/10.1037/0022-3514.37.1.97

Chen, J., Yang, X., \& Smith, R.E. (2016). The effects of creativity on advertising wear-in and wear-out. Journal of the Academy of Marketing Science, 44(3), 334-349. https://doi.org/10.1007/s11747-014-0414-5

DatarePortal. (2020). Digital 2020: Jordan. Retrieved from https://datareportal.com/ reports/digital-2020-jordan

Dickinger, A., Haghirian, P., Murphy, J., \& Scharl, A. (2004, January). An investigation and conceptual model of SMS marketing. In Proceedings of the 37th Annual Hawaii International Conference on System Sciences, 2004. 05-08, January Hawaii: IEEE.

Duncan, C.P., \& Nelson, J.E. (1985). Effects of humor in a radio advertising experiment. Journal of Advertising, 14(2), 33-64. https://doi.org/10.1080/00913367.1985.10 672944

eMarketer. (2015). Number of companies using Instagram to nearly double next yea will surpass Twitter in 2017. Retrieved from https://www.emarketer.com/Article/ Number-of-Companies-Using-Instagram-Nearly-Double-Next-Year/1013122

Fornell, C., \& Larcker, D.F. (1981). Evaluating structural equation models with unobservable variables and measurement error. Journal of Marketing Research, 18(1), 39-50. https://doi.org/10.2307/3150980
Försch, S., \& De Haan, E. (2018). Targeting online display ads: Choosing their frequency and spacing. International Journal of Research in Marketing, 35(4), 661-672. https://doi.org/10.1016/j.ijresmar.2018.09.002

Gaber, H.R., Wright, L.T., \& Kooli, K. (2019). Consumer attitudes towards Instagram advertisements in Egypt: The role of the perceived advertising value and personalization. Cogent Business \& Management, 6(1), 1618431. https://doi.org/ 10.1080/23311975.2019.1618431

Gebreselassie, A.W., \& Bougie, R. (2019). Increasing the effectiveness of advertisements targeting social issues in least developed countries. Journal of Social Marketing, 9(2), 225-251. https://doi.org/10.1108/JSOCM-01-2018-0001

Grewal, D., Bart, Y., Spann, M., \& Zubcsek, P.P. (2016). Mobile advertising: A framework and research agenda. Journal of Interactive Marketing, 34, 3-14. https://doi. org/10.1016/j.intmar.2016.03.003

Goldstein, D.G., Suri, S., McAfee, R.P., Ekstrand-Abueg, M., \& Diaz, F. (2014). The economic and cognitive costs of annoying display advertisements. Journal of Marketing Research, 51(6), 742-752. https://doi.org/10.1509/jmr.13.0439

Gupta, B.B., Agrawal, D.P., \& Yamaguchi, S. (2019). Deep learning models for human centered computing in fog and mobile edge networks. Journal of Ambient Intelligence and Humanized Computing, 10, 2907-2911. https://doi.org/10.1007/ s12652-018-0919-8

Gupta, B.B., Yamaguchi, S., \& Agrawal, D.P. (2018). Advances in security and privacy of multimedia big data in mobile and cloud computing. Multimedia Tools and Applications, 77(7), 9203-9208. https://doi.org/10.1007/s11042-018-6426-2

Ha, L. (1996). Advertising clutter in consumer magazines: Dimensions and effects. Journal of Advertising Research, 36(4), 76-85.

Hair, J.F., Hult, G.T.M., Ringle, C.M., \& Sarstedt, M. (2017). A primer on partial least squares structural equation modeling (PLS-SEM) (2nd edn.). Thousand Oaks, CA: Sage.

Henseler, J., Hubona, G., \& Ray, P.A. (2016). Using PLS path modeling in new technology research: Updated guidelines, Industrial Management \& Data Systems, 16(1), 2-20. https://doi.org/10.1108/IMDS-09-2015-0382

Hinson, R., Boateng, H., Renner, A., \& Kosiba, J.P.B. (2019). Antecedents and consequences of customer engagement on Facebook: An attachment theory perspective. Journal of Research in Interactive Marketing, 13(2), 204-226. https:// doi.org/10.1108/JRIM-04-2018-0059

Hofstede, G.H., Hofstede, G.J., \& Minkov, M. (2005). Cultures and organizations Software of the mind (Vol. 2). New York, NY: Mcgraw-hill.

Hollebeek, L.D., Glynn, M.S., \& Brodie, R.J. (2014). Consumer brand engagement in social media: Conceptualization, scale development and validation. Journal of Interactive Marketing, 28(1), 149-165. https://doi.org/10.1016/j.intmar.2013.12.002

Internet World Stats. (2020). Internet growth and population statistics. Retrieved from https://www.internetworldstats.com/list2.htm

Jahmani, K., Fadiya, S.O., Abubakar, A.M., \& Elrehail, H. (2018). Knowledge content quality, perceived usefulness, KMS use for sharing and retrieval. VINE Journal of Information and Knowledge Management Systems, 48(4), 470-490. https://doi. org/10.1108/VJIKMS-08-2017-0054

Jararweh, Y., Alsmirat, M., Al-Ayyoub, M., Benkhelifa, E., Darabseh, A., Gupta, B., \& Doulat, A. (2017). Software-defined system support for enabling ubiquitous mobile edge computing. The Computer Journal, 60(10), 1443-1457. https://doi. org/10.1093/comjnl/bxx019

Kalliny, M. (2012). What advertisers need to know about promotion in the Arab world: Technology and media perspectives. Journal of Promotion Management, 18(4), 436-457. https://doi.org/10.1080/10496491.2012.715124

Kaya, B., Abubakar, A.M., Behravesh, E., Yildiz, H., \& Mert, I.S. (2020). Antecedents of innovative performance: Findings from PLS-SEM and fuzzy sets (fSQCA). Journal of Business Research, 114, 278-289. https://doi.org/10.1016/j.jbusres.2020.04.016

Kaya, B., Behravesh, E., Abubakar, A.M., Kaya, O.S., \& Orús, C. (2019). The moderating role of website familiarity in the relationships between e-service quality, e-satisfaction and e-loyalty. Journal of Internet Commerce, 18(4), 369-394. https://doi.org/10.1080/15332861.2019.1668658

Keiningham, T., Aksoy, L., \& Williams, L. (2009). Why loyalty matters. Dallas, TX: BenBella Books.

Kronrod, A. \& Huber, J. (2019). Ad wearout wearout: How time can reverse the negative effect of frequent advertising repetition on brand preference. International Journal of Research in Marketing, 36(2), 306-324. https://doi. org/10.1016/j.jijesmar.2018.11.008

Li, H., Edwards, S.M., \& Lee, J.H. (2002). Measuring the intrusiveness of advertisements: Scale development and validation. Journal of Advertising, 31(2), 37-48. https:// doi.org/10.1080/00913367.2002.10673665

Lin, H., \& Chen, Z. (2015). Influence of SMS advertising on consumer behavioral intention. Journal of Organizational and End User Computing (JOEUC), 27(4), 25-42. https://doi.org/10.4018/JOEUC.2015100102

Magin, S., Algesheimer, R., Huber, F., \& Herrmann, A. (2003) The impact of brand personality and customer satisfaction on customer's loyalty: Theoretical approach and findings of a causal analytical study in the sector of internet service providers. Electronic Markets, 13(4), 294-308. https://doi.org/10.1080/10196780320 00135572

Mahajan, V. (2013). Understanding the Arab consumer. Harvard Business Review, 91(5), 128-133.

Mostafa, M.M. (2011). An investigation of Egyptian consumers' attitudes toward ethical issues in advertising. Journal of Promotion Management, 17(1), 42-60. https://doi.org/10.1080/10496491.2011.553776

Mahmoud, A.B. (2013). Syrian consumers: Beliefs, attitudes, and behavioral responses to internet advertising. Vers/as: Teorija ir Praktika, 14(4), 297-307. https://doi. org/10.3846/btp.2013.31 
Mahmoud, A.B. (2015). E-mail advertising in Syria: Assessing beliefs, attitudes, and behaviors. Journal of Promotion Management, 21(6), 649-665. https://doi.org/ 10.1080/10496491.2015.1055044

Mahmoud, A.B., Grigoriou, N., Fuxman, L., Hack-Polay, D., Mahmoud, F.B., Yafi, E., \& Tehseen, S. (2019). Email is evil! Journal of Research in Interactive Marketing, 13(2), 227-248. https://doi.org/10.1108/JRIM-09-2018-0112

Mahmoud, A.B., Grigoriou, N., Fuxman, L., \& Reisel, W.D. (2020). Political advertising effectiveness in war-time Syria. Media, War \& Conflict, 13(4), 375-398. https:// doi.org/10.1177/1750635219841356

Noble, S.M., Griffith, D.A., \& Adjei, M.T. (2006). Drivers of local merchant loyalty: Understanding the influence of gender and shopping motives. Journal of Retailing, 82(3), 177-188. https://doi.org/10.1016/j.jretai.2006.05.002

Nordhielm, C.L. (1996). A dual-process model of advertising repetition effects. In M.L., Scott, \& R. Batra (Eds.), Persuasive imagery: A consumer response perspective. Norwood, NJ: Lawrence Erlbaum Associates.

Podsakoff, P.M., MacKenzie, S.B., \& Podsakoff, N.P. (2012). Sources of method bias in social science research and recommendations on how to control it. Annual Review of Psychology, 63, 539-569. https://doi.org/10.1146/annurev-psych-120710-100452

Pechmann, C., \& Stewart, D.W. (1990). The effects of comparative advertising on attention, memory, and purchase intentions. Journal of Consumer Research, 17(2), 180-191. https://doi.org/10.1086/208548

Peggy, M. (1999). The wearout phenomenon. Marketing Research, 11(3), 26-32.

Rau, P.L.P., Zhou, J., Chen, D., \& Lu, T.P. (2014). The influence of repetition and time pressure on effectiveness of mobile advertising messages. Telematics and Informatics, 31(3), 463-476. https://doi.org/10.1016/j.tele.2013.10.003

Riaz, Z., \& Khan, M.I. (2016). Impact of service failure severity and agreeableness on consumer switchover intention: Mediating role of consumer forgiveness. Asia Pacific Journal of Marketing and Logistics, 28(3), 420-434. https://doi.org/ 10.1108/APJML-07-2015-0106

Ringle, C.M., Wende, S., \& Becker, J.M. (2015). SmartPLS 3. Boenningstedt: SmartPLS $\mathrm{GmbH}$.

Romani, S., Grappi, S., \& Dalli, D. (2012). Emotions that drive consumers away from brands: Measuring negative emotions toward brands and their behavioral effects. International Journal of Research in Marketing, 29(1), 55-67. https://doi. org/10.1016/j.ijresmar.2011.07.001

Royo-Vela, M., \& Luna, G. (2012). The antecedents of negative consumers' attitudes toward SMS advertising: A theoretical framework. Palma de Mallorca: Actas deIXXIV Encuentro de Profesores de Marketing.

Royo-Vela, M., \& Meyer, F. (2016). Exploring wearout and some insights and replies to factors affecting irritation and attitudes towards mobile advertising. In P. De Limited, pp. 211-241. https://doi.org/10.1108/978-1-78560-313-620151010

Schmidt, S., \& Eisend, M. (2015). Advertising repetition: A meta-analysis on effective frequency in advertising. Journal of Advertising, 44(4), 415-428. https://doi.org/ $10.1080 / 00913367.2015 .1018460$
Shankar, A., \& Jebarajakirthy, C. (2019). The influence of e-banking service quality on customer loyalty: A moderated-mediation approach. International Journal of Bank Marketing, 37(5), 1119-1142. https://doi.org/10.1108/IJBM-03-2018-0063

Shanahan, T., Tran, T.P., \& Taylor, E.C. (2019). Getting to know you: Social media personalization as a means of enhancing brand loyalty and perceived quality. Journal of Retailing and Consumer Services, 47, 57-65. https://doi.org/10.1016/ j.jretconser.2018.10.007

Shawky, S., Kubacki, K., Dietrich, T., \& Weaven, S. (2019). Using social media to create engagement: A social marketing review. Journal of Social Marketing, 9(2), 204-224. https://doi.org/10.1108/JSOCM-05-2018-0046

Shmueli, G., Sarstedt, M., Hair, J.F., Cheah, J.H., Ting, H., Vaithilingam, S., \& Ringle C.M. (2019). Predictive model assessment in PLS-SEM: Guidelines for using PLS predict. European Journal of Marketing, 53(11), 2322-2347. https://doi. org/10.1108/EJM-02-2019-0189

Srinivasan, S., Pauwels, K., Silva-Risso, J., \& Hanssens, D.M. (2009). Product innovations, advertising, and stock returns. Journal of Marketing, 73(1), 24-43. https://doi.org/10.1509/jmkg.73.1.024

Statista. (2019). Number of social network users worldwide from 2010 to 2021 (in billions). Retrieved from https://www.statista.com/statistics/278414/numberof-worldwide-social-network-users/

Sung, B., \& Yih, J. (2019). The direct and indirect effects of anger and its cognitive appraisals in public relations incidents. Asia Pacific Journal of Marketing and Logistics, 31(5), 1344-1358. https://doi.org/10.1108/APJML-08-2018-0292

Triantafillidou, A., \& Siomkos, G. (2018). The impact of Facebook experience on consumers' behavioral brand engagement. Journal of Research in Interactive Marketing, 12(2), 164-192. https://doi.org/10.1108/JRIM-03-2017-0016

Tsai, J.Y., Egelman, S., Cranor, L., \& Acquisti, A. (2011). The effect of online privacy information on purchasing behavior: An experimental study. Information Systems Research, 22(2), 254-268. https://doi.org/10.1287/isre.1090.0260

Tucker, C.E. (2014). Social networks, personalized advertising, and privacy controls. Journal of Marketing Research, 51(5), 546-562. https://doi.org/10.1509/jmr.10.0355

Walrave, M., Poels, K., Antheunis, M.L., Van Den Broeck, E., \& Van Noort, G. (2018). Like or dislike? Adolescents' responses to personalized social network site advertising. Journal of Marketing Communications, 24(6), 599-616. https://doi org/10.1080/13527266.2016.1182938

Wipulanusat, W., Panuwatwanich, K., Stewart, R.A., Arnold, S.L., \& Wang, J. (2020). Bayesian network revealing pathways to workplace innovation and career satisfaction in the public service. Journal of Management Analytics, 7(2), 253-280. https://doi.org/10.1080/23270012.2020.1749900

Yakubu, M.N., Dasuki, S.I., Abubakar, A.M., \& Kah, M.M. (2020). Determinants of learning management systems adoption in Nigeria: A hybrid SEM and artificial neural network approach. Education and Information Technologies, 25, 1-25. https://doi.org/10.1007/s10639-020-10110-w

Zhao, X., Lynch, Jr, J.G., \& Chen, Q. (2010). Reconsidering Baron and Kenny: Myths and truths about mediation analysis. Journal of Consumer Research, 37(2), 197-206. https://doi.org/10.1086/651257 


\section{Appendix 1}

TABLE 1-A1: Research instruments.

\begin{tabular}{|c|c|c|}
\hline Instruments & Factor loadings & $t$ \\
\hline \multicolumn{3}{|l|}{ Mobile ad wearout } \\
\hline 'This brand has the tendency to send mobile ads several times' & 0.908 & 82.021 \\
\hline 'This brand repeatedly sends the same mobile ads through (i.e., Facebook, Instagram, Twitter etc.)' & 0.945 & 139.320 \\
\hline 'I keep receiving the same mobile ads from this brand' & 0.914 & 81.419 \\
\hline \multicolumn{3}{|l|}{ Consumer irritation } \\
\hline 'I consider mobile advertising messages as annoying' & 0.941 & 108.815 \\
\hline 'I consider mobile advertising messages as irritating' & 0.941 & 128.516 \\
\hline \multicolumn{3}{|l|}{ Consumer perceived intrusiveness } \\
\hline 'I perceive mobile advertisements as disturbing' & 0.950 & 227.301 \\
\hline 'I perceive mobile advertisements as intrusive' & 0.940 & 122.579 \\
\hline \multicolumn{3}{|l|}{ Consumer engagement } \\
\hline 'Using online brand community gets me to think about the brand' $\dagger$ & - & - \\
\hline 'I think about this online brand community a lot when I'm using it' & 0.675 & 9.765 \\
\hline 'This online brand community stimulates my interest to learn more about products/services' & 0.663 & 9.136 \\
\hline 'Using this online brand community makes me happy' & 0.789 & 19.151 \\
\hline 'I feel good when I use this online brand community' & 0.658 & 11.713 \\
\hline 'I'm proud to use this online brand community' $\dagger$ & - & - \\
\hline 'I spend a lot of time using this online brand community compared to others' $\dagger$ & - & - \\
\hline \multicolumn{3}{|l|}{ Consumer loyalty } \\
\hline 'As a customer, I am strongly loyal to this brand' & 0.804 & 25.285 \\
\hline 'In general, the brand I do business with show loyalty to me as a customer' & 0.710 & 14.024 \\
\hline 'I usually feel an attachment to the brand with which I do business' & 0.855 & 25.457 \\
\hline
\end{tabular}

$\dagger$, Deleted items. 